\title{
Effects of smoking cessation on gastric emptying in smokers
}

Kadota Koichiro, $\mathrm{MD}^{1)}$, Takeshima Fuminao, $\mathrm{MD}, \mathrm{PhD}^{1)}$, Inoue Keita, $\mathrm{MD}^{1)}$, Takamori Ken-ichi, $\mathrm{MD}, \mathrm{PhD}^{2)}$, Yoshioka Sumako, $\mathrm{MD}, \mathrm{PhD}^{1)}$, Nakayama Seiko, $\mathrm{MD}, \mathrm{PhD}^{1)}$, Abe Koh, $\mathrm{MD}, \mathrm{PhD}^{1)}$, Mizuta Yohei, $\mathrm{MD}, \mathrm{PhD}^{2)}$, Kohno Shigeru, $\mathrm{MD}, \mathrm{PhD}^{2)}$, and Ozono Yoshiyuki, $\mathrm{MD}, \mathrm{PhD}^{1)}$

${ }^{1)}$ Department of General Medicine and ${ }^{2)}$ Second Department of Internal Medicine, Nagasaki University School of Medicine, Nagasaki, Japan

The authors have no conflict of interests to declare.

This work was supported by a Grant-in-Aid from the Japan Society for the Promotion of Science (No. 17590597 and 20590704).

Running title: Accelerated gastric emptying after smoking cessation

Key words: gastric emptying; smoking cessation

Corresponding author: Takeshima Fuminao, $\mathrm{MD}, \mathrm{PhD}$

Department of General Medicine, Nagasaki University School of Medicine

1-7-1 Sakamoto, Nagasaki 852-8501, Japan

Phone: (095) 819-7591; Fax: (095) 819-7597

E-mail: ftake@net.nagasaki-u.ac.jp 


\section{SUMMARY}

Background: Smoking cessation can lead to changes in appetite and weight gain in some patients; thus, smoking cessation may alter gastrointestinal motility. Effects of smoking cessation on gastric emptying in smokers have not been established.

Aim: The present study sought to determine how smoking cessation affects gastric emptying in smokers.

Methods: Subjects comprised 53 habitual smokers and 12 healthy nonsmokers. Habitual smokers were treated for 2 months with transdermal nicotine patches. Gastric emptying was studied using ${ }^{13} \mathrm{C}$ acetate breath tests at the beginning of the study, and at 1 week and 9 weeks after cessation of patch use. Maximal ${ }^{13} \mathrm{CO}_{2}$ excretion time $\left(\mathrm{T}_{\max }\right),{ }^{13} \mathrm{CO}_{2}$ excretion half-life $\left(\mathrm{T}_{1 / 2}\right)$, and parameters $\beta$ and $\kappa$, representing initial and subsequent gastric-emptying phases, respectively, were determined using conventional formulae.

Results: Before smoking cessation, $\mathrm{T}_{\max }$ was reached significantly later in smokers $(0.94 \pm$ $0.3 \mathrm{~h}, P=0.014)$ than in controls $(0.89 \pm 0.1 \mathrm{~h})$. At 1 week after the end of treatment, $\mathrm{T}_{\max }$ was significantly decreased (from $1.05 \pm 0.32 \mathrm{~h}$ to $0.72 \pm 0.64 \mathrm{~h}, P=0.003$ ). $\mathrm{T}_{1 / 2}$ also tended to decrease, but not significantly. While $\beta$ was decreased significantly (from $2.46 \pm 0.40$ to $2.17 \pm 0.58, P=0.022), \kappa$ was unchanged. However, by 9 weeks after the end of treatment, $\mathrm{T}_{\max }(1.28 \pm 0.69 \mathrm{~h})$ had increased to levels seen before treatment.

Conclusion: Smoking cessation temporarily accelerates gastric emptying, and decreases in $\beta$ suggest that initial-phase gastric emptying accelerates after smoking cessation. The temporary acceleration of gastric emptying after smoking cessation may be involved in the temporary increase in appetite and weight gain seen after smoking cessation. 


\section{INTRODUCTION}

Tobacco smoking is associated with a number of gastrointestinal disorders $(1,2)$. Nicotine is the principal active component in tobacco and nicotine exposure is often considered to be synonymous with smoking. The pharmacological effects of nicotine have been elucidated for several gastrointestinal disorders $(1,2)$. For peptic ulcers, nicotine stimulates pepsinogen and vasopressin secretion, reduces mucosal blood flow and suppresses mucosal restitution. For gastroesophageal reflux disease (GERD), nicotine decreases lower esophageal sphincter pressure and distal esophageal peristalsis.

The effects of smoking and nicotine on gastric emptying remain controversial. Gritz et al. (3) and Miller et al. (4) reported that smoking delays gastric emptying of solids, particularly during the initial phase, according to scintigraphy. A precise study using dual scintigraphy by Scott et al. (5) also demonstrated that acute smoking produces antrofundal redistribution and delays gastric emptying of solid and liquid meals. However, Wong et al. (6) reported that acute transdermal nicotine administration does not affect gastric emptying of solids and liquids according to gastric scintigraphy. A study by Sanaka et al. using the

${ }^{13} \mathrm{C}$-octanic acid breath test (7) demonstrated that acute smoking accelerates gastric emptying in the later phase.

The general consensus is that smoking cessation can lead to some degree of appetite and weight gain. A positive association between gastric emptying and appetite has been suggested $(8,9)$. Smoking cessation thus seems likely to alter gastrointestinal motility. However, the effects of smoking cessation on gastric emptying in smokers have not been established. The present study sought to determine how smoking cessation affects gastric emptying in smokers.

\section{MATERIALS AND METHODS}




\section{Patients}

In this study, we defined habitual smokers as current smokers who smoke over 10 packs years (calculated as packs per day $\times$ smoking years, or as cigarettes per day $\times$ smoking years/20). Subjects comprised 53 habitual smokers (41 men, 12 women; mean age, $46 \pm 16$ years; range, 20 - 74 years), and 18 healthy never-smoker controls (14 men, 4 women; mean age, $46 \pm 18$ years; range, $24-75$ years). Subjects received no remuneration, but habitual smokers received nicotine patches at no cost.

Habitual smokers were treated for 8 weeks with transdermal nicotine patches (Nicotinell TTS, Novartis Pharma K.K., Tokyo, Japan ). They used 52.5-mg patches for a total of 4 weeks, 35-mg patches for 2 weeks, and 17.5-mg patches for 2 weeks. After treatment was started, patients were not allowed to smoke. We discontinued treatment and excluded subjects from the study if they resumed smoking. Body weight and height were measured, and BMI was calculated in smokers at the beginning of the study, and at 1 and 9 weeks after cessation of the nicotine patch. Ten-centimeter visual-analogue scale data for appetite before breakfast $(0 \mathrm{~cm}$ refers to the weakest appetite, and $10 \mathrm{~cm}$ indicates the greatest appetite) were also obtained from smokers at each point. None of the subjects were being treated with painkillers, antidepressants, hormone drugs or medicines for the stomach or bowels. Patients with diabetes mellitus, endocrine disease, renal failure, pregnancy, severe obesity (body mass index $\left.(\mathrm{BMI})>40 \mathrm{~kg} / \mathrm{m}^{2}\right)$, cachexia, alcohol abuse or a past history of gastrointestinal surgery were excluded from this study. Presence of serum immunoglobulin (Ig)G antibody to $H$. pylori was examined by enzyme immunoassay (SRL, Tokyo, Japan). The study protocol was approved by the Medical Ethics Committee of Nagasaki University. Written informed consent was obtained from each subject in accordance with the Helsinki Declaration. 


\section{Gastric emptying}

Gastric emptying was measured using the ${ }^{13} \mathrm{C}$ acetate breath test at 09:00 following an overnight fast. Briefly, patients ingested a liquid test meal (OKUNOS-A; $200 \mathrm{kcal} / 200 \mathrm{ml}$; Forica Foods, Niigata, Japan) labeled with $100 \mathrm{mg}$ of sodium ${ }^{13} \mathrm{C}$-acetate (Sodium Acetate (1-13C,99\%); Euriso-Top, Saint-Aubin, France). Breath samples for ${ }^{13} \mathrm{CO}_{2}$ measurements were collected in air bags at baseline (before test meal) and at 10-min intervals for $2 \mathrm{~h}$ after intake of the test meal. Analysis of isotopic enrichment was performed using an isotope ratio mass spectrometer with an online gas chromatographic purification system (UBiT-IR 200; Otsuka Pharmaceuticals, Tokyo, Japan). The ${ }^{13} \mathrm{CO}_{2}$ excretion per minute rate curve was mathematically fitted to a conventional formula of $y(t)=m * \kappa * \beta * e^{-k^{*} t^{*}}\left(1-e^{-\kappa * \tau}\right)^{\beta-1}$. In this equation, "y" indicates the cumulative percentage of ${ }^{13} \mathrm{CO}_{2}$ excretion in breath at time $\mathrm{t}(\mathrm{h})$ and " $\mathrm{m}$ ", “ $\kappa$ " and " $\beta$ " are estimated parameters, with " $\mathrm{m}$ " being the total cumulative ${ }^{13} \mathrm{C}$ recovery when time is infinite. A larger (smaller) $\beta$ indicates slower (faster) emptying in the early phase, and a larger (smaller) $\kappa$ indicates faster (slower) emptying in the later phase. Maximal ${ }^{13} \mathrm{CO}_{2}$ excretion time $\left(\mathrm{T}_{\max }=[\ln \beta] / \kappa\right)$, which is the time of maximal ${ }^{13} \mathrm{CO}_{2}$ recovery in the breath samples, and ${ }^{13} \mathrm{CO}_{2}$ excretion half-life $\left(\mathrm{T}_{1 / 2}=-\left[\ln \left(1-2^{-1 / \beta}\right)\right] / \kappa\right)$, which is the time when half of the (for infinite time extrapolated) cumulative ${ }^{13} \mathrm{CO}_{2}$ recovery is reached, were also calculated $(10,11)$.

Gastric emptying was studied at the beginning of the study, and at 1 and 9 weeks after cessation of the nicotine patch.

\section{Statistical analysis}

All data are expressed as means \pm standard deviation. Differences between groups were examined for statistical significance using Student's $t$-test and the Wilcoxon signed-ranks test. Values of $P<0.05$ denote the presence of a statistically significant 
difference. All statistical analyses were performed using SPSS v15.0 software (SPSS Japan, Tokyo, Japan).

\section{RESULTS}

\section{Delayed rate of gastric emptying in smokers}

We initially compared the rate of gastric emptying between smokers and controls. Demographically, no significant differences were found in smokers and controls with regard to age, gender or presence of $H$. pylori using the serum antibody test. Mean $\mathrm{T}_{\max }$ was $0.94 \pm$ $0.3 \mathrm{~h}$ for smokers $(\mathrm{n}=53)$ and $0.89 \pm 0.1 \mathrm{~h}$ for controls $(\mathrm{n}=18) . \mathrm{T}_{\max }$ was reached significantly later in smokers than in controls $(P=0.014$, Student's $t$-test) (Fig. 1).

\section{$T_{\max }$ and $T_{1 / 2}$ decrease temporarily after smoking cessation}

All 53 habitual smokers were treated with transdermal nicotine patches. Side effects such as nausea, headache, insomnia and skin reactions were observed during patch use. Most subjects tolerated these side effects, but 1 patient stopped using the nicotine patch due to skin reactions. Of the 53 smokers, 22 smokers succeeded in quitting until 9 weeks after cessation of patch use, whereas 31 smokers failed to quit (9 smokers succeeded in quitting until 1 week after cessation of patch use, but began smoking again, while 22 smokers resumed smoking during patch use). Only data from the 22 subjects who successfully quit smoking was analyzed.

Body weight and BMI increased by a mean of $1.8 \pm 2.0 \mathrm{~kg}$ and $0.6 \pm 0.8 \mathrm{~kg} / \mathrm{m}^{2}$ at 1 week after the end of treatment, and an additional $0.7 \pm 1.2 \mathrm{~kg}$ and $0.3 \pm 0.5 \mathrm{~kg} / \mathrm{m}^{2}$ at 9 weeks after the end of treatment. Appetite measured by visual-analogue scale also increased by a mean of $1.5 \pm 2.4 \mathrm{~cm}$ at 1 week after the end of treatment and had decreased by $0.1 \pm 1.7 \mathrm{~cm}$ at 9 weeks after the end of treatment (Table 1). 
Next, we compared the rates of gastric emptying in the 22 successful quitters between the beginning of the study and 1 or 9 weeks after cessation of patch use. At 1 week after the end of treatment, $\mathrm{T}_{\max }$ decreased significantly from $1.05 \pm 0.32 \mathrm{~h}$ to $0.72 \pm 0.64 \mathrm{~h}(\mathrm{n}=22, P$ $=0.003$, Wilcoxon signed-ranks test). However, by 9 weeks after the end of treatment, $\mathrm{T}_{\max }$ $(1.28 \pm 0.69 \mathrm{~h}, \mathrm{n}=22)$ had again increased, and no differences were apparent between values before and after smoking cessation (Fig. 2). As with $\mathrm{T}_{\max }, \mathrm{T}_{1 / 2}$ also showed a decrease from $1.66 \pm 0.50 \mathrm{~h}$ to $1.53 \pm 0.43 \mathrm{~h}$ by 1 week after the end of treatment. However, this change was not significant $(\mathrm{n}=22, P=0.058$, Wilcoxon signed-ranks test). By 9 weeks after the end of treatment, $\mathrm{T}_{1 / 2}(1.89 \pm 0.53 \mathrm{~h}, \mathrm{n}=22)$ had again increased, and no differences were apparent between values before and after cessation of smoking (Fig. 3).

\section{$\beta$, not but $\kappa$, temporarily decreased after smoking cessation}

At 1 week after the end of the treatment, parameter $\beta$ decreased significantly from $2.46 \pm 0.40$ to $2.16 \pm 0.58(\mathrm{n}=22, \mathrm{P}=0.022$, using the Wilcoxon signed-rank test $)$. The decrease in $\beta$ suggests that gastric emptying in the initial phase accelerates after smoking cessation. However, by 9 weeks after the end of the treatment, $\beta(2.21 \pm 0.40, n=22)$ again increased, and there were no differences were seen between the values before and after smoking cessation (Fig. 4). Parameter $\kappa$ showed no differences between before cessation $(0.90 \pm 0.21, \mathrm{n}=22)$ and 1 week $(0.88 \pm 0.22, \mathrm{n}=22)$ or 9 weeks $(0.85 \pm 0.28, \mathrm{n}=22)$ after the end of treatment (Fig. 5).

\section{DISCUSSION}

The present study offers the first prospective examination of the effects of smoking cessation on gastric emptying in smokers. One week after the end of treatment, the rate of gastric emptying of liquid was significantly accelerated, particularly in the initial phase, as 
compared with before smoking cessation. To understand the mechanisms underlying smoking cessation-evoked acceleration of gastric emptying, we need to determine the effects of chronic exposure to tobacco on gastric emptying. However, few reports have examined the chronic effects of smoking on gastric emptying. Hanson et al. (12) reported that smokers display a shorter gastric emptying half-life than nonsmokers using scintigraphy. The present study found that $\mathrm{T}_{\max }$ was significantly longer in smokers than in nonsmokers.

Conflicting results from a previous report (12) may have been due to the smaller subject population (under one-third of that in the present study) or differences in patient characteristics (only middle-aged men in the previous report). Numerous studies $(13,14)$ have shown that chronic exposure to tobacco is associated with sympathetic over-activity, which can contribute to various cardiovascular diseases. Not only does an acute and prominent increase in heart rate occur after smoking, but also a persistent increase is seen throughout the day (13). Heart rate variability is reportedly reduced among chronic smokers (15). Sympathetic overactivity in smokers may inhibit gastric emptying. In contrast to sympathetic overactivity in chronic smokers, smoking cessation appears to reduce the sympathetic bias. A decrease in heart rate (16) and an increase in heart rate variability (15) have been reported. Although the mechanisms underlying smoking cessation-evoked acceleration in gastric emptying are uncertain, re-emergence of vagal activity may work as one possible key player.

A second explanation is based on nitric oxide (NO). Levels of exhaled NO are known to be decreased in smokers $(17,18)$. Hogman et al. (19) demonstrated that endogenous production of NO in the airways was increased after smoking cessation and was restored to normal values after 4 weeks without smoking. Endogenous NO plays an important role as a nonadrenergic, noncholinergic inhibitory neurotransmitter in the GI tract (20). The relaxation role of endogenous NO during gastric adaptation to a meal in the proximal stomach has been 
clearly established $(21,22)$. NO is also known to cause relaxation of the pylorus $(20)$. Relaxation of the pylorus following gastric distension plays an important role in regulation of gastric emptying. Previous studies have shown that NO synthase inhibitors delay gastric emptying of solids or liquids in rats (23) and dogs (24-26). The increase in endogenous NO after smoking cessation may cause relaxation of the pylorus and accelerate gastric emptying. Further studies assessing levels of mRNA expression in the pylorus after smoking cessation are thus warranted.

We did not simultaneously obtain ${ }^{13} \mathrm{C}$ acetate breath test data and gastric scintigraphy data in order to minimize radiation exposure in our subjects. The ${ }^{13} \mathrm{C}$ acetate breath test was developed as a nonradioactive alternative for measurement of gastric emptying, and has been confirmed to correrate well with gastric scintigraphy $(11,27)$. It is known that gastric emptying is a complex process with different mechanisms of emptying for liquids and solids (28). In the present study, we only evaluated gastric emptying of liquids using the ${ }^{13} \mathrm{C}$ acetate breath test. As this is an easy, reliable and inexpensive procedure for measuring gastric emptying, many scientists, including ourselves, have used it to study gastric emptying in various pathological cases (29-31). Sarnelli et al. (32) demonstrated that delayed gastric emptying for both solids and liquids occurs in $15.4 \%$ of functional dyspepsia (FD) patients, delayed emptying of solids alone occurs in $6.4 \%$ and delayed emptying of liquids alone occurs in $20 \%$. Because the pattern of emptying for liquids does not always predict emptying for solids, evaluation of gastric emptying for solids is necessary to confirm our findings.

Various studies (33) have found evidence that smoking cessation is associated with weight gain and have agreed that weight gain is greater at 1 - 2 months following cessation. Most studies (34) have shown that smoking cessation increases appetite (food intake), which is considered to be one of the causes of weight gain after cessation. In this study, we confirmed that smoking cessation increases body weight and appetite, particularly at 1 week 
after the end of treatment, when gastric emptying for liquids is accelerated. Bergmann et al. (8) and Horowitz et al. (9) found a positive correlation between gastric emptying and appetite. The temporary acceleration of gastric emptying for liquids after smoking cessation demonstrated in the present study may be involved in the temporary increase in appetite and weight gain after smoking cessation. Further evaluation of the mechanisms underlying accelerated gastric emptying is essential to clarify how gastric emptying is involved in temporary weight gain after smoking cessation.

It has been reported that delayed gastric emptying is present in approximately $40 \%$ of FD patients (35). Although the pathophysiology of FD remains unknown, delayed gastric emptying has been implicated. Sarnelli et al. (32) reported that dyspeptic patients showed delayed gastric emptying for liquids, which is associated postprandial fullness and severe early satiety. Smoking cessation should thus be recommended to FD patients who smoke, as the acceleration in gastric emptying and change in appetite after smoking cessation could resolve the delayed emptying associated with early satiety in FD patients. 


\section{REFERENCES}

1. Thomas GA, Rhodes J, Ingram JR. Mechanisms of disease: nicotine--a review of its actions in the context of gastrointestinal disease. Nat Clin Pract Gastroenterol Hepatol $2005 ; 2: 536-544$.

2. $\mathrm{Wu} \mathrm{WK}$, Cho $\mathrm{CH}$. The pharmacological actions of nicotine on the gastrointestinal tract. J Pharmacol Sci 2004;94:348-358.

3. Gritz ER, Ippoliti A, Jarvik ME, et al. The effect of nicotine on the delay of gastric emptying. Aliment Pharmacol Ther 1988;2:173-178.

4. Miller G, Palmer KR, Smith B, et al. Smoking delays gastric emptying of solids. Gut 1989;30:50-53.

5. Scott AM, Kellow JE, Shuter B, et al. Effects of cigarette smoking on solid and liquid intragastric distribution and gastric emptying. Gastroenterology 1993;104:410-416.

6. Wong PW, Kadakia SC, McBiles M. Acute effect of nicotine patch on gastric emptying of liquid and solid contents in healthy subjects. Dig Dis Sci 1999;44:2165-2171.

7. Sanaka M, Anjiki H, Tsutsumi H, et al. Effect of cigarette smoking on gastric emptying of solids in Japanese smokers: a crossover study using the ${ }^{13} \mathrm{C}$-octanoic acid breath test. J Gastroenterol 2005;40:578-582.

8. Bergmann JF, Chassany O, Petit A, et al. Correlation between echographic gastric emptying and appetite: influence of psyllium. Gut 1992;33:1042-1043.

9. Horowitz M, Jones K, Edelbroek MA, et al. The effect of posture on gastric emptying and intragastric distribution of oil and aqueous meal components and appetite. Gastroenterology 1993;105:382-390.

10. Ghoos YF, Maes BD, Geypens BJ, et al. Measurement of gastric emptying rate of solids by means of a carbon-labeled octanoic acid breath test. Gastroenterology 1993; 104:1040-1647. 
11. Braden B, Adams S, Duan L, et al. The $\left[{ }^{13} \mathrm{C}\right]$ acetate breath test accurately reflects gastric emptying of liquids in both liquids and semisolid test meals. Gastroenterology 1995;108:1048-1055.

12. Hanson M, Lilja B. Gastric emptying in smokers. Scand J Gastroenterol $1987 ; 22: 1102-1104$.

13. Benowitz NL. Cigarette smoking and cardiovascular disease: pathophysiology and implications for treatment. Prog Cardiovasc Dis 2003;46:91-111.

14. Yun AJ, Bazar KA, Lee PY, et al. The smoking gun: many conditions associated with tobacco exposure may be attributable to paradoxical compensatory autonomic responses to nicotine. Med Hypotheses 2005;64:1073-1079.

15. Stein PK, Rottman JN, Kleiger RE. Effect of $21 \mathrm{mg}$ transdermal nicotine patches and smoking cessation on heart rate variability. Am J Cardiol 1996;77:701-705.

16. Hughes JR, Hatsukami D. Signs and symptoms of tobacco withdrawal. Arch Gen Psychiatry 1986;43:289-294.

17. Persson MG, Zetterstrom O, Agrenius V, et al. Single-breath nitric oxide measurements in asthmatic patients and smokers. Lancet 1994;343:146-147.

18. Schilling J, Holzer P, Guggenbach M, et al. Reduced endogenous nitric oxide in the exhaled air of smokers and hypertensives. Eur Respir J 1994;7:467-471.

19. Hogman M, Holmkvist $\mathrm{T}$, Walinder R, et al. Increased nitric oxide elimination from the airways after smoking cessation. Clin Sci (Lond) 2002;103:15-19.

20. Takahashi T. Pathophysiological significance of neuronal nitric oxide synthase in the gastrointestinal tract. J Gastroenterol 2003;38:421-430.

21. Tonini M, De Giorgio R, De Ponti F, et al. Role of nitric oxide- and vasoactive intestinal polypeptide-containing neurones in human gastric fundus strip relaxations. $\mathrm{Br} J$ Pharmacol 2000;129:12-20. 
22. Kuiken SD, Vergeer M, Heisterkamp SH, et al. Role of nitric oxide in gastric moter and sensory functions in healthy subjects. Gut 2002;51:212-218.

23. Plourde V, Quintero E, Suto G, et al. Delayed gastric emptying induced by inhibitors of nitric oxide synthase in rats. Eur J Pharmacol 1994;256:125-129.

24. Orihata M, Sarna SK. Inhibition of nitric oxide synthase delays gastric emptying of solid meals. J Pharmacol Exp Ther 1994;271:660-670.

25. Anvari M, Paterson CA, Daniel EE. Role of nitric oxide mechanisms in control of pyloric motility and transpyloric flow of liquids in conscious dogs. Dig Dis Sci 1998;43:506-512.

26. Tanaka T, Mizumoto A, Itoh Z. Effects of nitric oxide synthase inhibitor on the digestive system measured by simultaneous monitoring of gastric motility, gastric emptying activity and postprandial pancreaticobiliary secretion in dogs. Exp Anim 2005;54:309-317.

27. Gatti C, Federichi di Abriola F, Dall'Oglio L, et al. Is the ${ }^{13} \mathrm{C}$-acetate breath test a valid procedure to analyse gastric emptying in children? J Pediatr Surg 2000;35:62-65.

28. Mayer EA. The physiology of gastric storage and emptying. In: Johnson LR, ed. Physiology of the Gastrointestinal Tract. New York: Raven; 1994:926-976.

29. Shimamoto C, Hirata I, Hiraike Y, et al. Evaluation of gastric motor activity in the elderly by electrogastrography and the ${ }^{13} \mathrm{C}$-acetate breath test. Gerontology 2002;48:381-386. 30. Takamori K, Mizuta Y, Takeshima F, et al. Relation among plasma ghrelin level, gastric emptying, and psychologic condition in patients with functional dyspepsia. J Clin Gastroenterol 2007;41:477-483.

31. Inamori M, Akiyama T, Akimoto K, et al. Early effects of pepper mint oil on gastric emptying : a crossover study using a continuous real time ${ }^{13} \mathrm{C}$ breath test (BreathID system). $J$ Gastroenterol 2007;42:539-542.

32. Sarnelli G, Caenepeel P, Geypens B, et al. Symptoms associated with impaired gastric 
emptying of solids and liquids in functional dyspepsia. Am J Gastroenterol 2003;98:783-788. 33. Filozof C, Fernandez Pinilla MC, Fernandez-Cruz A. Smoking cessation and weight gain. Obes Rev 2004;5:95-103.

34. Jo YH, Talmage DA, Role LW. Nicotinic receptor-mediated effects on appetite and food intake. J Neurobiol 2002;53:618-632.

35. Quartero AO, de Wit NJ, LodderAC, et al. Disturbed solid-phase gastric emptying in functional dyspepsia: a meta-analysis. Dig Dis Sci 1998;43:2028-2033. 
FIGURE LEGENDS

$$
\mathrm{T}_{\max }(\mathrm{h})
$$

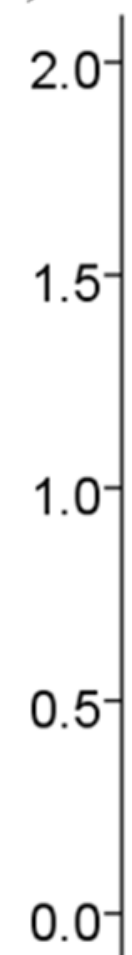

$$
P=0.014
$$

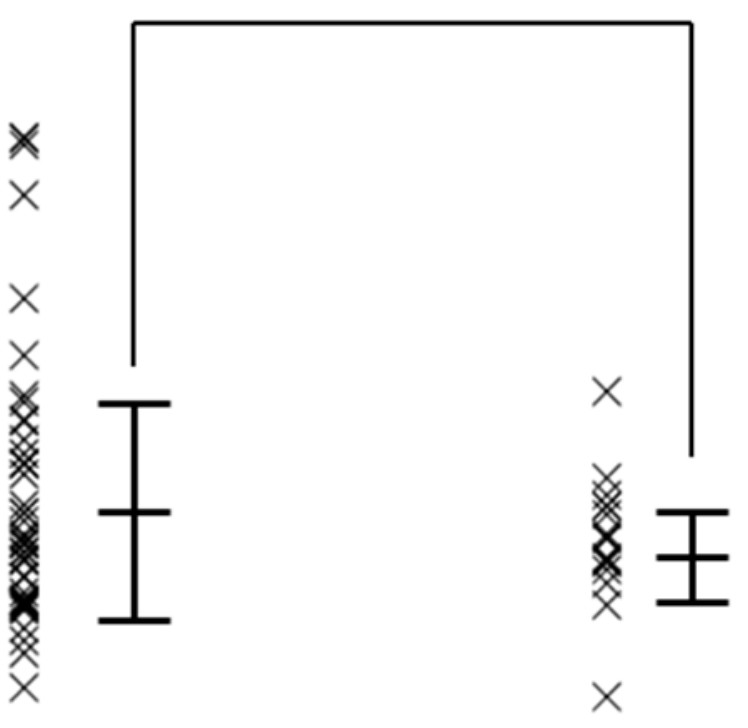

Smokers

$$
(\mathrm{n}=53)
$$

\section{Controls}

$$
(\mathrm{n}=18)
$$

Figure 1: Gastric emptying as measured by the ${ }^{13} \mathrm{C}$ acetate breath test in smokers $(\mathrm{n}=53)$ and healthy nonsmoker controls $(\mathrm{n}=18)$. Point $\mathrm{X}$ shows $\mathrm{T}_{\max }$ of individual patients and bars indicate mean and standard deviation. Mean $\mathrm{T}_{\max }$ was $0.94 \pm 0.3 \mathrm{~h}$ for smokers and $0.89 \pm 0.1$ $\mathrm{h}$ for controls. $\mathrm{T}_{\max }$ was significantly longer in smokers than in controls $(P=0.014)$. 


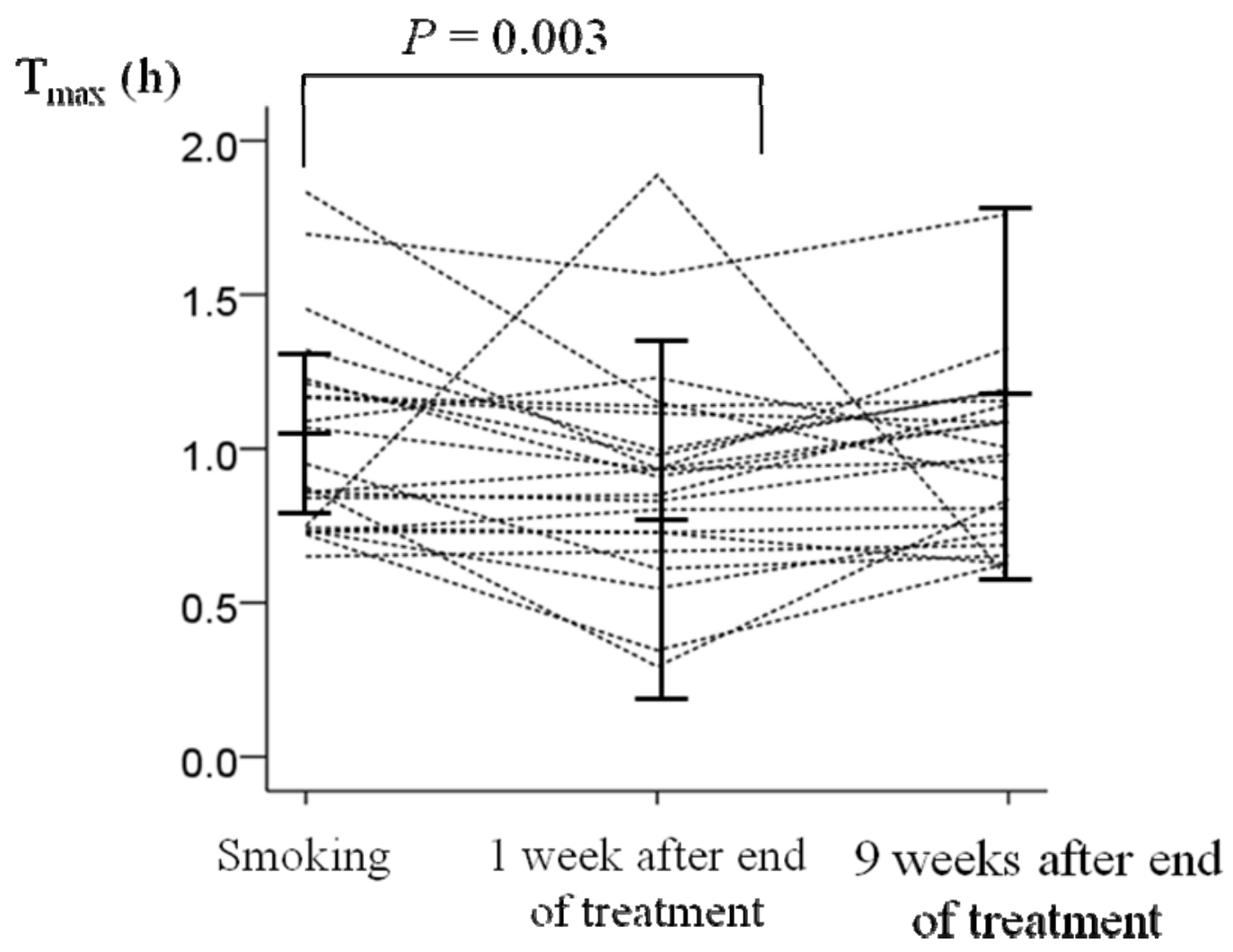

Figure 2: $T_{\max }$ before and after smoking cessation. At 1 week after the end of treatment, $T_{\max }$ had decreased significantly from $1.05 \pm 0.32 \mathrm{~h}$ to $0.72 \pm 0.64 \mathrm{~h}(P=0.003)$. However, by 9 weeks after the end of treatment, $\mathrm{T}_{\max }$ had again increased to $1.28 \pm 0.69 \mathrm{~h}$, with no significant difference when compared to values before smoking cessation. 


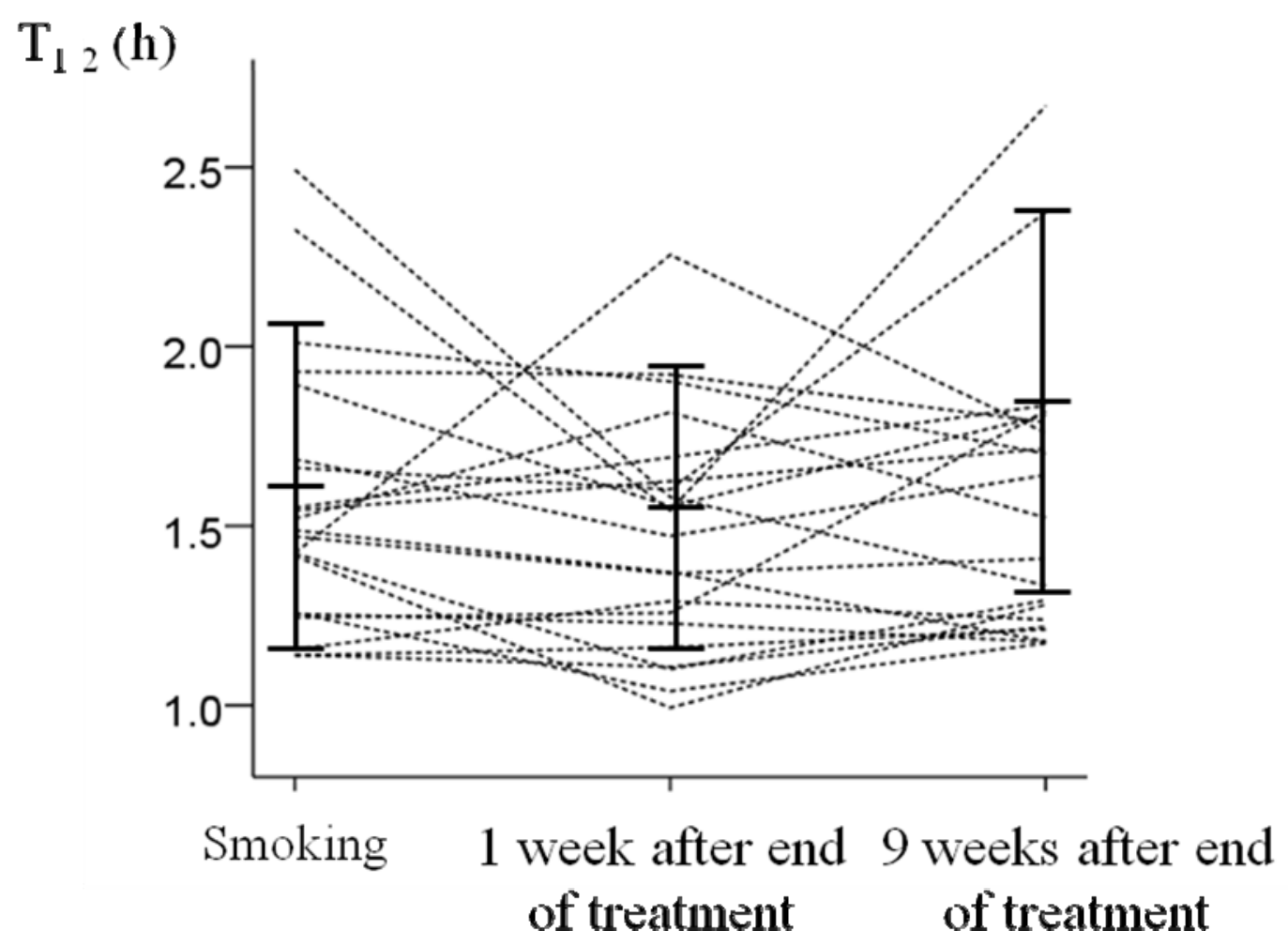

Figure 3: $T_{1 / 2}$ before and after smoking cessation. At 1 week after the end of treatment, $T_{1 / 2}$ showed a decreasing tendency, from $1.66 \pm 0.50 \mathrm{~h}$ to $1.53 \pm 0.43 \mathrm{~h}$. This difference was not significant $(P=0.058)$. By 9 weeks after the end of treatment, $\mathrm{T}_{1 / 2}$ had increased to $1.89 \pm$ $0.53 \mathrm{~h}$, with no significant difference when compared to values before smoking cessation. 


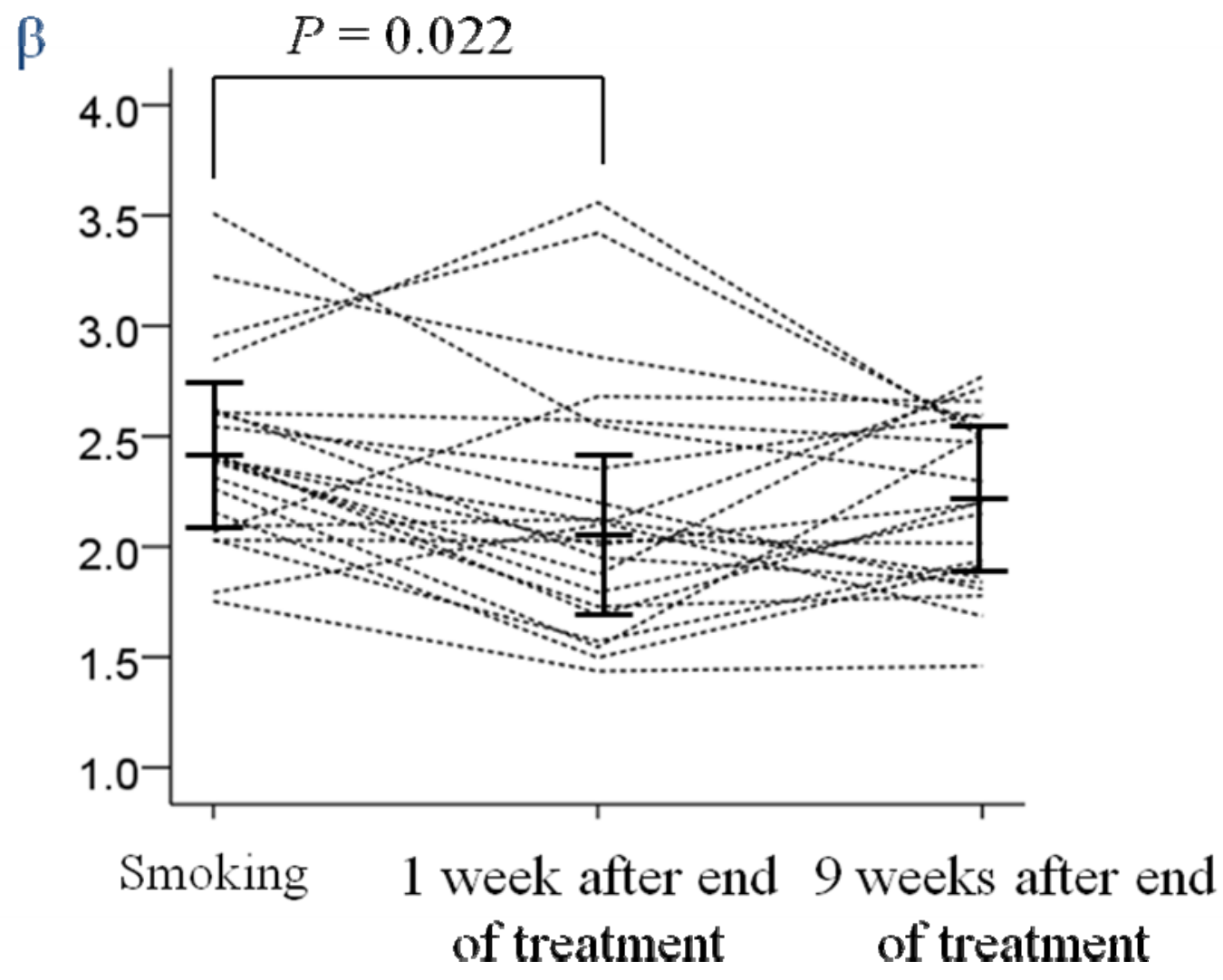

Figure 4: Parameter $\beta$ before and after smoking cessation. At 1 week after the end of treatment, parameter $\beta$ had decreased significantly from $2.46 \pm 0.40$ to $2.16 \pm 0.58(P=$ 0.022). However, by 9 weeks after the end of treatment, $\beta$ had increased to $2.21 \pm 0.40$, showing no significant difference when compared to values before smoking cessation. 


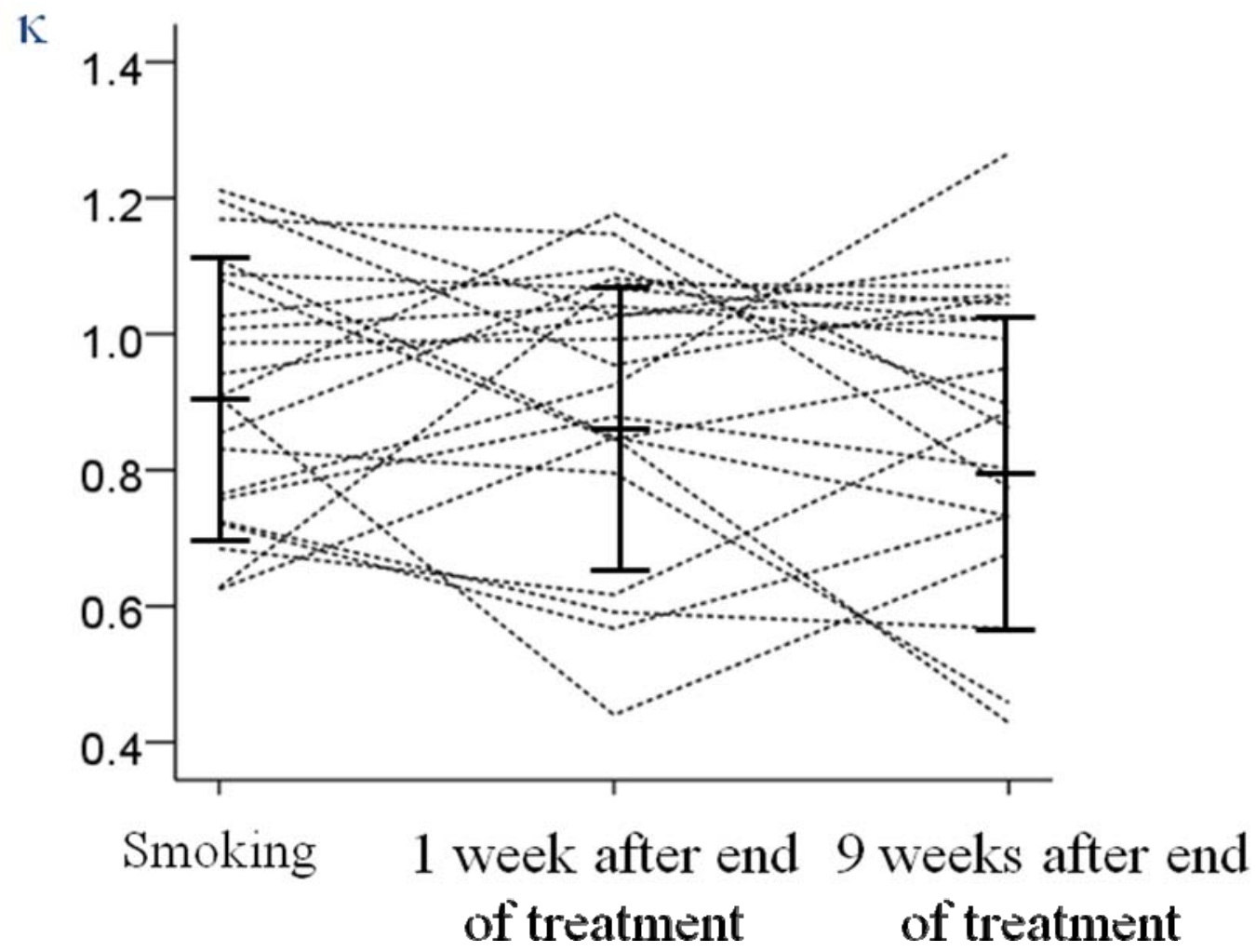

Figure 5: Parameter $\kappa$ before and after smoking cessation. Parameter $\kappa$ showed no differences before $(0.90 \pm 0.21)$, or at either 1 week $(0.88 \pm 0.22, \mathrm{n}=22)$ or 9 weeks $(0.85 \pm$ $0.28, \mathrm{n}=22)$ after the end of treatment. 
Table 1. Changes in body weight, BMI and appetite after smoking cessation

\begin{tabular}{|c|c|c|c|c|}
\hline Characteristics & Baseline & \multicolumn{3}{|c|}{$\begin{array}{l}1 \text { week after the } 9 \text { weeks after the } \\
\text { end of treatment end of treatment }\end{array}$} \\
\hline Body weight $(\mathrm{kg})$ & \multicolumn{2}{|c|}{$65.7 \pm 12.6$} & $2.5^{\star}$ & $68.3 \pm 12.3^{*}$ \\
\hline BMI $\left(\mathrm{kg} / \mathrm{m}^{2}\right)$ & $23.4 \pm 3.7$ & $24.0 \pm 3.7^{*}$ & \multicolumn{2}{|c|}{$24.3 \pm 3.5^{\star}$} \\
\hline Appetite (cm) & $5.7 \pm 2.0$ & 7.2 & & $7.1 \pm 2.0^{*}$ \\
\hline
\end{tabular}

${ }^{\star} P<0.05$ vs. baseline 